University of Wollongong

Research Online

Australian Institute for Innovative Materials -

Papers

Australian Institute for Innovative Materials

$1-1-2018$

Stabilized antiferroelectricity in xBiSc03-(1-x)NaNbO3 lead-free ceramics with established double hysteresis loops

Lisheng Gao

Pennsylvania State University

Hanzheng Guo

Pennsylvania State University

Shujun Zhang

University of Wollongong, shujun@uow.edu.au

Clive A. Randall

Pennsylvania State University

Follow this and additional works at: https://ro.uow.edu.au/aiimpapers

Part of the Engineering Commons, and the Physical Sciences and Mathematics Commons

Research Online is the open access institutional repository for the University of Wollongong. For further information contact the UOW Library: research-pubs@uow.edu.au 


\title{
Stabilized antiferroelectricity in xBiSc03-(1-x)NaNbO3 lead-free ceramics with established double hysteresis loops
}

\author{
Abstract \\ We previously reported various solid solution systems that demonstrated the stabilized antiferroelectric \\ $(\mathrm{P})$ phases in $\mathrm{NaNbO} 3$ through lowering the tolerance factor. However, all those reported modifications \\ were achieved by adding A 2+ B 4+ 03 type solid solutions. A lead-free antiferroelectric (AFE) solid \\ solution $\mathrm{xBiScO} 3-(1-\mathrm{x}) \mathrm{NaNbO} 3$ was rationalized by adopting the tolerance factor design rule. \\ Specifically, adding BiScO 3 was found to effectively stabilize the AFE phase without changing the crystal \\ symmetry of $\mathrm{NaNbO} 3$. Microstructure and electron zone axis diffraction patterns from transmission \\ electron microscopy revealed the stabilized AFE $(P)$ phase in this solid solution. Besides, the electric-field- \\ induced polarization with a double-hysteresis loop was observed. The present results pointed out that the \\ strategy could also be applied while adding A 3+ B 3+ 03 type solid solutions. In addition, it expanded the \\ compositional design that can be applied to antiferroelectric materials.

\section{Disciplines} \\ Engineering | Physical Sciences and Mathematics

\section{Publication Details} \\ Gao, L., Guo, H., Zhang, S. \& Randall, C. A. (2018). Stabilized antiferroelectricity in xBiScO3-(1-x)NaNbO3 \\ lead-free ceramics with established double hysteresis loops. Applied Physics Letters, 112 (9), \\ 092905-1-092905-5.
}




\section{Stabilized antiferroelectricity in $\mathrm{xBiScO}_{3}-(1-\mathrm{x}) \mathrm{NaNbO}_{3}$ lead-free ceramics with established double hysteresis loops}

Lisheng Gao, Hanzheng Guo, Shujun Zhang, and Clive A. Randall

Citation: Appl. Phys. Lett. 112, 092905 (2018); doi: 10.1063/1.5017697

View online: https://doi.org/10.1063/1.5017697

View Table of Contents: http://aip.scitation.org/toc/apl/112/9

Published by the American Institute of Physics

\section{Articles you may be interested in}

Flexible high energy density capacitors using La-doped $\mathrm{PbZrO}_{3}$ anti-ferroelectric thin films

Applied Physics Letters 112, 092901 (2018); 10.1063/1.5018003

Effects of high pressure nitrogen annealing on ferroelectric $\mathrm{Hf}_{0.5} \mathrm{Zr}_{0.5} \mathrm{O}_{2}$ films

Applied Physics Letters 112, 092906 (2018); 10.1063/1.5003369

0.6ST-0.4NBT thin film with low level Mn doping as a lead-free ferroelectric capacitor with high energy storage performance

Applied Physics Letters 112, 093902 (2018); 10.1063/1.5020679

Enhanced energy storage density by inducing defect dipoles in lead free relaxor ferroelectric $\mathrm{BaTiO}_{3}$-based ceramics

Applied Physics Letters 110, 132902 (2017); 10.1063/1.4979467

Temperature induced phase transformations and negative electrocaloric effect in $(\mathrm{Pb}, \mathrm{La})(\mathrm{Zr}, \mathrm{Sn}, \mathrm{Ti}) \mathrm{O}_{3}$ antiferroelectric single crystal

Journal of Applied Physics 122, 154101 (2017); 10.1063/1.4986849

Domain disruption and defect accumulation during unipolar electric fatigue in a BZT-BCT ceramic Applied Physics Letters 111, 252902 (2017); 10.1063/1.5008619

\section{Scilight}

Sharp, quick summaries illuminating the latest physics research

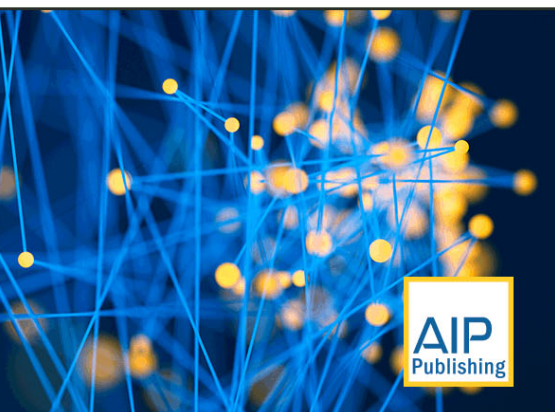




\title{
Stabilized antiferroelectricity in $\mathrm{xBiScO}_{3}-(1-\mathrm{x}) \mathrm{NaNbO}_{3}$ lead-free ceramics with established double hysteresis loops
}

\author{
Lisheng Gao, ${ }^{1}$ Hanzheng Guo, ${ }^{1}$ Shujun Zhang, ${ }^{2}$ and Clive A. Randall ${ }^{1}$ \\ ${ }^{1}$ Center for Dielectrics and Piezoelectrics, Materials Research Institute, The Pennsylvania State University, \\ University Park, Pennsylvania 16802, USA \\ ${ }^{2}$ Institute for Superconducting and Electronic Materials, Australian Institute of Innovative Materials, \\ University of Wollongong, Wollongong, NSW 2522, Australia
}

(Received 29 November 2017; accepted 17 February 2018; published online 2 March 2018)

\begin{abstract}
We previously reported various solid solution systems that demonstrated the stabilized antiferroelectric $(\mathrm{P})$ phases in $\mathrm{NaNbO}_{3}$ through lowering the tolerance factor. However, all those reported modifications were achieved by adding $\mathrm{A}^{2+} \mathrm{B}^{4+} \mathrm{O}_{3}$ type solid solutions. A lead-free antiferroelectric (AFE) solid solution $\mathrm{xBiScO}_{3}-(1-\mathrm{x}) \mathrm{NaNbO}_{3}$ was rationalized by adopting the tolerance factor design rule. Specifically, adding $\mathrm{BiScO}_{3}$ was found to effectively stabilize the AFE phase without changing the crystal symmetry of $\mathrm{NaNbO}_{3}$. Microstructure and electron zone axis diffraction patterns from transmission electron microscopy revealed the stabilized AFE (P) phase in this solid solution. Besides, the electric-field-induced polarization with a double-hysteresis loop was observed. The present results pointed out that the strategy could also be applied while adding $\mathrm{A}^{3+} \mathrm{B}^{3+} \mathrm{O}_{3}$ type solid solutions. In addition, it expanded the compositional design that can be applied to antiferroelectric materials. Published by AIP Publishing. https://doi.org/10.1063/1.5017697
\end{abstract}

In the 1950s, Kittel predicted the existence of antiferroelectricity. ${ }^{1}$ In antiferroelectric (AFE) materials, although the ions are spontaneously polarized, the adjacent translational anti-parallel polarizing directions that constitute a superstructure describe the unit cell. Therefore, in an AFE material, there is no macroscopic polarization. $\mathrm{PbZrO}_{3}(\mathrm{PZ})$ is a well-known AFE material and has been commercialized for capacitor applications. ${ }^{2}$ AFE materials have an increased permittivity under a high electric field $(\mathrm{dP} / \mathrm{dE}>0)$, where the field induced AFE-FE phase transition under an electric field boosts the electrostatic energy density. ${ }^{3}$

Early work by Nicholson and Cross ${ }^{4}$ on $\mathrm{NaNbO}_{3}$ reported that in single crystals, a double hysteresis could be observed, but later this has become difficult to verify with both crystals and ceramics. $\mathrm{NaNbO}_{3}$ has an AFE P (space group Pbma) phase at ambient conditions, ${ }^{5-9}$ however, the double hysteresis loops are rarely observed in $\mathrm{NaNbO}_{3}$ due to the existence of a metastable ferroelectric (FE) Q (space group P $2{ }_{1} \mathrm{ma}$ ) phase. ${ }^{10-16}$ It is further noted that a stabilized AFE phase requires a lower tolerance factor (t). ${ }^{16-21}$ The calculation of the Goldschmidt tolerance factor in an $\mathrm{ABO}_{3}$ type perovskite is shown in Eq. (1), where $r_{A}, r_{B}$, and $r_{O}$ are the ionic radii of $\mathrm{A}$-site ions, $\mathrm{B}$-site ions, and oxygen ions, respectively. ${ }^{16}$ The Shannon-Prewitt ionic radii ${ }^{22}$ are applied for the twelvefold and sixfold coordination for A and B sites, respectively,

$$
t=\frac{r_{A}+r_{O}}{\sqrt{2}\left(r_{B}+r_{O}\right)} .
$$

It has been experimentally observed that the polar order can be tuned into antipolar order by decreasing the $t$. The lead-free $\mathrm{BiFeO}_{3}$ is a good example; the polar $\mathrm{R} 3 \mathrm{c}$ phase was transformed into a $\mathrm{PbZrO}_{3}$-like antipolar phase after adding rare earth elements to lower $t .^{23-25}$ It was found that the rule could also be applied to $\mathrm{NaNbO}_{3}$, and we predicted a broad range of different solid solution compositions that should host the AFE behavior. Recently, our group has demonstrated that AFE behavior could be obtained by adding $\mathrm{CaHfO}_{3},{ }^{10} \mathrm{SrZrO}_{3},{ }^{11}$ and $\mathrm{CaZrO}_{3},{ }^{12,15}$ which can effectively decrease the tolerance factor and then stabilize the AFE phase in $\mathrm{NaNbO}_{3}$. The observed zone axis electron diffraction patterns and electric field induced signature AFE double hysteresis P-E loops verified the validity for the $\mathrm{NaNbO}_{3}$ material system. However, these verifications were all based on using the $\mathrm{A}^{2+} \mathrm{B}^{4+} \mathrm{O}_{3}$-type end members. In this work, $\mathrm{A}^{3+} \mathrm{B}^{3+} \mathrm{O}_{3^{-}}$ type $\mathrm{BiScO}_{3}$ will be used as an alternative end member to modify $\mathrm{NaNbO}_{3}$. X-ray diffraction (XRD) spectra, phase compositions, and electric properties will be evaluated. In addition, regarding the possible feasibility of commercial applications of $\mathrm{NaNbO}_{3}$ based lead-free ceramics, their performance inferiority compared to lead-based materials has to be considered carefully to meet application requirements.

The $\mathrm{xBiScO}_{3}-(1-\mathrm{x}) \mathrm{NaNbO}_{3} \quad(\mathrm{BSNN}-\mathrm{X}$ hereafter, $\mathrm{X}=100 \mathrm{x})$ solid solutions were prepared by conventional solid-state reaction. The raw chemicals were $\mathrm{Na}_{2} \mathrm{CO}_{3}$ (99.95\% Alfa Aesar, Ward Hill, MA), $\mathrm{Nb}_{2} \mathrm{O}_{5}$ (99.9\% Alfa Aesar, Ward Hill, MA), $\mathrm{Bi}_{2} \mathrm{O}_{3}$ (99.5\% Alfa Aesar, Ward Hill, MA), and $\mathrm{Sc}_{2} \mathrm{O}_{3}$ (99.95\% Alfa Aesar, Ward Hill, MA). 6 wt. $\%$ and 3 wt. $\%$ extra $\mathrm{Na}_{2} \mathrm{CO}_{3}$ and $\mathrm{Bi}_{2} \mathrm{O}_{3}$ were batched to compensate the volatilization during high-temperature processing, respectively. $\mathrm{Na}_{2} \mathrm{CO}_{3}$ was weighed and then ball milled in ethanol for $24 \mathrm{~h}$; afterward, $\mathrm{Nb}_{2} \mathrm{O}_{5}, \mathrm{Bi}_{2} \mathrm{O}_{3}$, and $\mathrm{Sc}_{2} \mathrm{O}_{3}$ were added and further ball milled for $24 \mathrm{~h}$. Then, the powder was dried at $80^{\circ} \mathrm{C}$ overnight to remove the ethanol. The batched powder was then calcined at $850^{\circ} \mathrm{C}$ for $3 \mathrm{~h}$ and then pressed into disk-shaped binder-free pellets. The pellets were sintered at $1350^{\circ} \mathrm{C}$ for $45 \mathrm{~min}$. XRD (PANalytical X'pert PRO) was used to examine the crystal phase purity of the sintered ceramics. The microstructure graphs were collected using a transmission electron microscope (TEM) (Philips EM420 
microscope) operating at $120 \mathrm{kV}$. The dielectric constant as a function of temperature was measured via the capacitance of parallel plate samples with known geometric parameters using an LCR meter (HP4284A, Agilent Technologies Inc., Santa Clara, CA) during both heating and cooling. The P-E loop was obtained using a Sawyer-Tower circuit; a sinusoidal field with $0.1 \mathrm{~Hz}$ was applied. The critical fields were determined by calculating the polarization current density.

Figure 1 shows the XRD spectra of $\mathrm{NaNbO}_{3}, \mathrm{BSNN}-1$, and BSNN-2; the peaks were indexed using a prototype cubic perovskite structure. As shown in Fig. 1(a), XRD plots of $\mathrm{NaNbO}_{3}$ and BSNN-1 are presented. It was found that all ceramics are phase pure without noticeable secondary phases. A close analysis of superlattice diffraction spectra at $2 \theta$ angles of $36.6^{\circ}$ and $55.2^{\circ}$ is presented in Fig. 1(b). These peaks at these two positions sequentially correspond to $\left\{\begin{array}{lll}1 & 1 & 3 / 4\end{array}\right\}$ and $\left\{\begin{array}{lll}2 & 1 & 3 / 4\end{array}\right\}$ AFE superlattice diffraction reflections. The AFE superlattice reflection peaks were observed in the $\mathrm{BiScO}_{3}$ modified $\mathrm{NaNbO}_{3}$ as well; it preliminarily implied that the AFE phase was obtained in BSNN.

Further studies on microstructures were carried out by Transmission Electron Microscopy (TEM). Micrographs and the corresponding selected area electron diffraction (SAED)
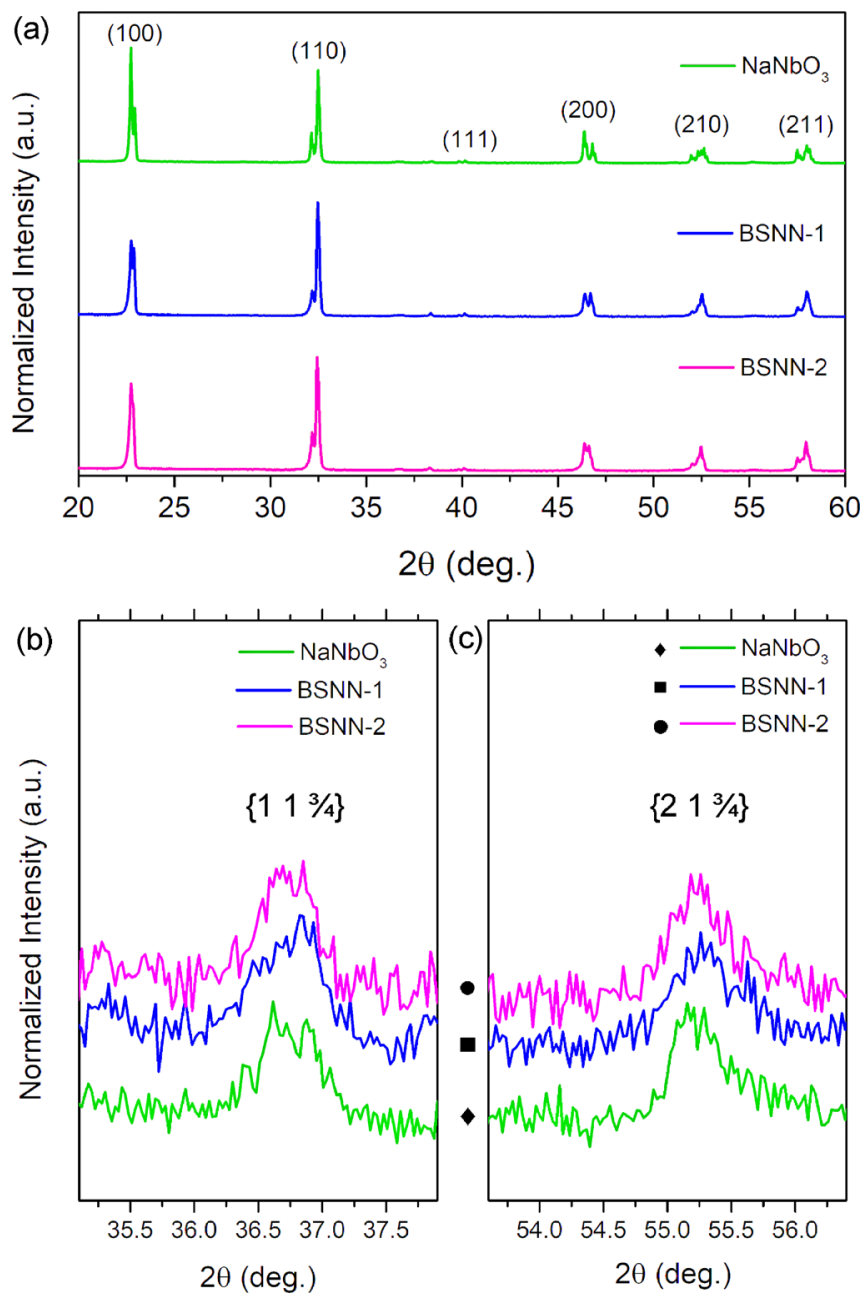

FIG. 1. X-ray diffraction spectra of (a) $\mathrm{NaNbO}_{3}, \mathrm{BSNN}-1$, and BSNN-2, (b) $\left\{\begin{array}{lll}1 & 1 & 3\end{array} / 4\right\}$ superlattice reflection at $2 \theta$ of $36.6^{\circ}$, and (c) $\{213 / 4\}$ superlattice reflection at $2 \theta$ of $55.2^{\circ}$. The peaks are indexed by the prototype cubic perovskite structure. patterns are shown in Fig. 2. The AFE $\mathrm{P}$ and FE Q phases were distinguished by the $\mathrm{B}$-site $\mathrm{Nb}$ ion displacement combining with oxygen octahedral tilting on the $b$ axis of the prototype cubic unit cell. ${ }^{5,26}$ The AFE $P$ phase can be denoted as a layered combination of $\mathrm{a}^{-} \mathrm{b}^{+} \mathrm{a}^{-}$and $\mathrm{a}^{-} \mathrm{b}^{-} \mathrm{a}^{-}$ in Glazer notation, and the FE Q phase is denoted as $\mathrm{a}^{-} \mathrm{b}^{+} \mathrm{a}^{-}{ }^{-5,27}$ The unit cell is quadrupled and doubled in $\mathrm{P}$ and $\mathrm{Q}$ phases along the [001] direction of perovskite unit cells, respectively. Consequentially, these enlarged superstructure unit cells display unique electron diffraction patterns. The $\mathrm{P}$ and $Q$ phases show the $1 / 4\{010\}$-type and $1 / 2\{010\}$-type diffraction patterns, respectively. ${ }^{26}$ Extensive TEM characterizations in our previous studies have clearly demonstrated that both the FE Q phase and the AFE P phase coexist in pure NN in the virgin state, which was suggested by the electron diffraction pattern analysis that the AFE $\mathrm{P}$ phase is present as the predominant phase, together with a small portion of the FE Q phase. ${ }^{10-12,14}$ The microstructures of $\mathrm{NaNbO}_{3}$ are shown again in Figs. 2(a) and 2(b). The crystal was composed of micron-sized domains in all compositions. The electron beams were aligned along the [100] zone axis to identify the AFE/FE nature by SAED. As unambiguously revealed by the electron diffraction pattern, the AFE $P$ phase and the FE Q phase were revealed by the $1 / 4\{010\}$ type diffraction spots [Figs. 2(e)-2(g)] and $1 / 2\{010\}$ superlattice spots [Fig. 2(h)], respectively, revealing the phase heterogeneity in $\mathrm{NaNbO}_{3}$ under ambient conditions. Diffuse scattering streaking along the [010] direction was observed in the SAED pattern of the $\mathrm{Q}$ phase, indicating the mesoscale nature of the FE Q phase here. ${ }^{10-14}$ As demonstrated in the previous studies, a small amount of dopants ( $\leq 6 \mathrm{~mol}$. \%), e.g., $\mathrm{CaZrO}_{3}, \mathrm{SrZrO}_{3}$, and $\mathrm{CaHfO}_{3}$, stabilized the AFE P phase over the FE Q phase, hence contributing to the double polarization hysteresis loops during bipolar electrical cycles. ${ }^{10-12}$ Similar to the systems mentioned above, $\mathrm{BiScO}_{3}$ doping in the present study was also found to enhance the antiferroelectric phase of $\mathrm{NaNbO}_{3}$, as revealed by the TEM micrographs shown in Figs. 2(c), 2(d), and 2(i)-2(k). Micron-sized domains of BSNN-1 are shown in Figs. 2(c) and 2(d), and the SAED patterns are shown in Figs. 2(i)-2(k). The symmetry of the AFE P phase was still preserved after $\mathrm{BiScO}_{3}$ doping. It was found that only $1 / 4\{010\}$ type superlattice spots were observed in BSNN-1, suggesting that the AFE phase was well stabilized in the $\mathrm{BiScO}_{3}$ modified $\mathrm{NaNbO}_{3}$. A close look at the SAED pattern of BSNN-1 revealed observable streaking along the [010] direction, which is marked by the rectangle in Fig. 2(k); the streaking could be identified as $1 / \mathrm{n}\{0 \mathrm{k} 0\}$ superlattice spots. It was believed that the streaking was associated with the incommensurate phase. ${ }^{28-30}$ The formation of the incommensurate AFE phase was observed in $\mathrm{Pb}$-based complex perovskites while changing the tolerance factor, order of $\mathrm{B}$ site cations, and the size difference between B-site ions, ${ }^{31-33}$ although it was found that the phase was affected by the degree of chemical order and the difference in B-site ionic radii in these cases. A similar incommensurate phase was also reported in the rareearth element doped $\mathrm{BiFeO}_{3}$ material system. ${ }^{25,34}$ Viehland et $a l .{ }^{35}$ considered that the formation of the incommensurate phase was a result of competition between the AFE phase and the FE phase, in the case of softening zone center (FE) and zone boundary (AFE) phonon modes. As a result, the 

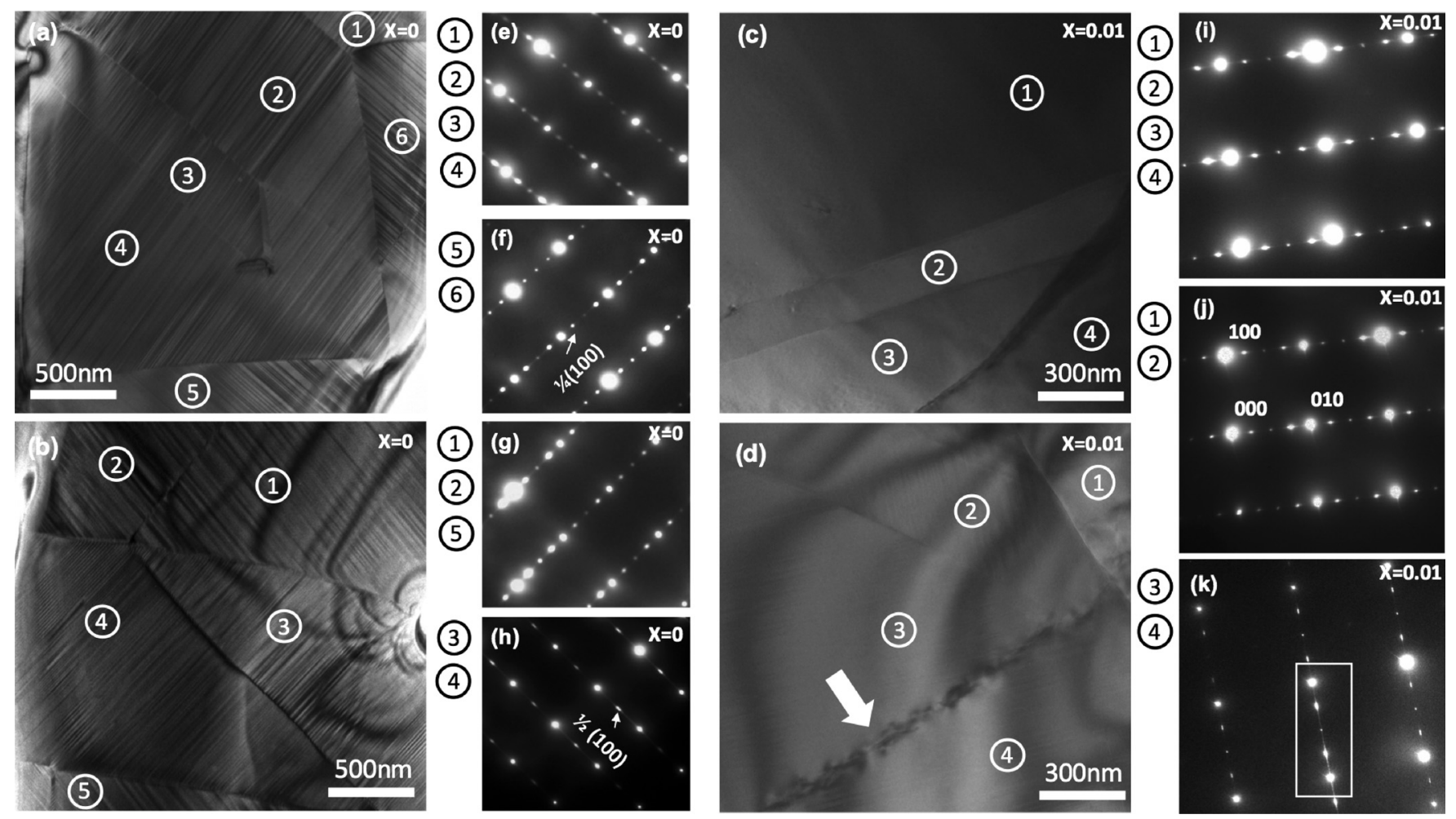

FIG. 2. TEM micrographs and selected area diffraction patterns: (a) and (b) domain structure of $\mathrm{NaNbO}_{3}$; (e), (f), and (g) $1 / 4\{010\}$ type diffractions, showing the AFE P phase in $\mathrm{NaNbO}_{3}$; (h) $1 / 2\{010\}$ type diffraction patterns, showing the FE Q phase in $\mathrm{NaNbO}_{3}$; (c) and (d) domain structure of BSNN-1; and (i)-(k) $1 / 4\{010\}$ type superlattice diffraction in BSNN-1. The index is based on the prototype cubic perovskite structure.

incommensurate phase was the result of the AFE and FE phases being a frustrated state due to their respective competition. ${ }^{34}$ The arrow in Fig. 2(d) shows dislocations along the grain boundaries.

The dielectric properties of BSNN-1 and BSNN-2 are shown in Fig. 3. Figure 3(a) presents the dielectric constant as a function of temperature. Dielectric anomalies were observed at $273{ }^{\circ} \mathrm{C}$ and $234^{\circ} \mathrm{C}$ in BSNN-1 and BSNN-2 during cooling, respectively, which could be attributed to the phase transition from the orthorhombic AFE R phase with the Pmnm space group to the orthorhombic AFE P phase with the Pbma space group. ${ }^{36,37}$ Together with some important parameters of previously reported $\mathrm{NaNbO}_{3}{ }^{12}$ and $\mathrm{xCaHfO}_{3}-(1-\mathrm{x}) \mathrm{NaNbO}_{3}(\mathrm{CHNN}-\mathrm{X})$ in Table $\mathrm{I},{ }^{10}$ the CurieWeiss law was adopted to extract important characteristics describing the phase transition; the details can be found in the previous work. ${ }^{10}$ It was found that the phase transition temperatures of both heating and cooling decreased due to the addition of $\mathrm{BiScO}_{3}$. A thermal hysteresis between heating and cooling processes was observed, consistent with the first order AFE-to-AFE (P-to-R) phase transitions. The ratio between the temperature gap $(\Delta \mathrm{T})$ of the hysteresis and the phase transition temperature during cooling $\left(\mathrm{T}_{2}\right)$ was calculated. Along with the previously reported data, it was found that this value increased with the lowering tolerance factor. It should be noted that BSNN-2 and CHNN-3 had almost identical tolerance factor values, and when took a further look at the Curie-Weiss temperature and the value of $\Delta \mathrm{T} / \mathrm{T}_{2}$, identical values were found for these two compositions, suggesting that the tolerance factor plays the dominated role in stabilizing the AFE phase. These observations are consistent with the theory proposed earlier by Levanyuk et al. ${ }^{38,39}$
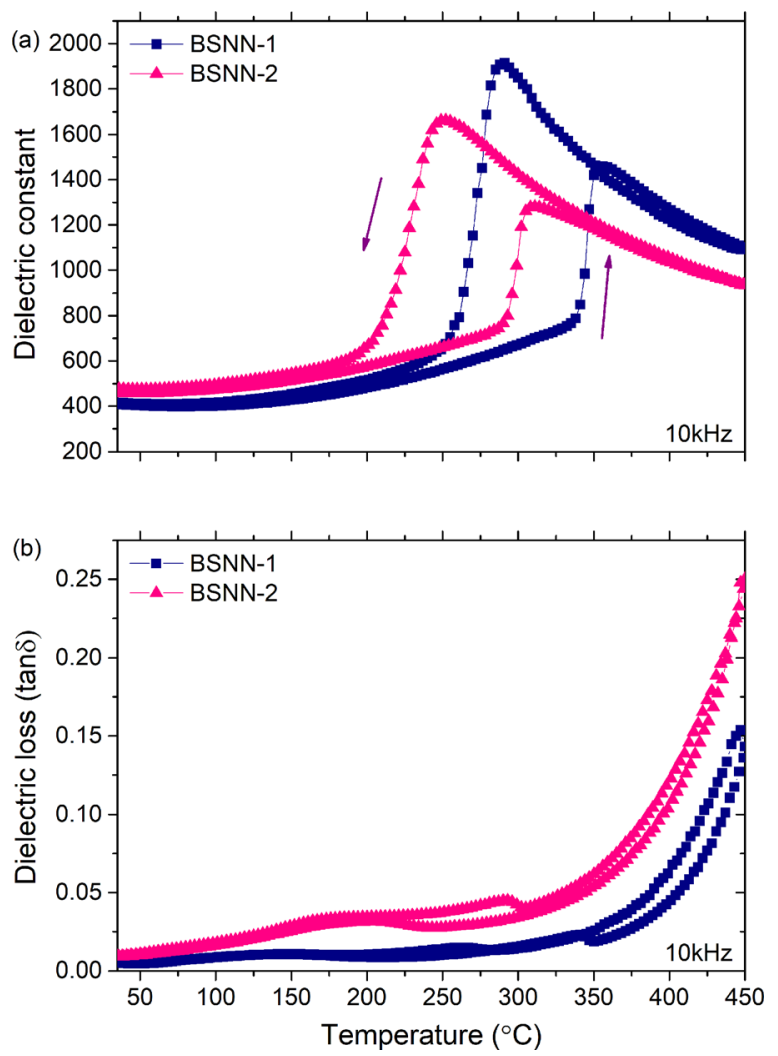

FIG. 3. (a) Dielectric constant as a function of temperature during heating and cooling, showing thermal hysteresis; the dielectric anomalies around $270^{\circ} \mathrm{C}$ and $230^{\circ} \mathrm{C}$ correspond to the first-order phase transitions from the AFE R phase to the AFE P phase. (b) Dielectric loss as a function of temperature during heating and cooling. 
TABLE I. Important parameters of the electric properties of $\mathrm{NaNbO}_{3}, \mathrm{CHNN}$, and BSNN. The parameters were calculated from the low-field and high-field dielectric properties. t, tolerance factor; $\mathrm{T}_{0}$, Curie-Weiss temperature; $\mathrm{C}$, Curie-Weiss constant; $\mathrm{T}_{1}$, phase transition temperature during heating; $\mathrm{T}_{2}$, phase transition temperature during cooling; $\Delta \mathrm{T}$, the difference between $\mathrm{T}_{1}$ and $\mathrm{T}_{2}$; and $\mathrm{E}_{\mathrm{F}}$ critical electric field to induce AFE-FE switching.

\begin{tabular}{lcccccccc}
\hline \hline Compositions & $\mathrm{t}$ & $\mathrm{T}_{0}\left({ }^{\circ} \mathrm{C}\right)$ & $\mathrm{C}\left(1 \times 10^{5} \cdot \mathrm{K}\right)$ & $\mathrm{T}_{1}\left({ }^{\circ} \mathrm{C}\right)$ & $\mathrm{T}_{2}\left({ }^{\circ} \mathrm{C}\right)$ & $\Delta \mathrm{T}\left({ }^{\circ} \mathrm{C}\right)$ & $\Delta \mathrm{T} / \mathrm{T}_{2}$ & $\mathrm{E}_{\mathrm{F}}(\mathrm{kV} / \mathrm{cm})$ \\
\hline $\mathrm{NaNbO}_{3}{ }^{10}$ & 0.9671 & 118 & 5.13 & 393 & 331 & 62 & 0.187 \\
BSNN-1 & 0.9664 & 108 & 3.47 & 344 & 273 & 71 & 0.260 \\
CSNN-2 $^{10}$ & 0.9657 & 31 & 3.70 & 299 & 225 & 74 & 0.329 \\
$\mathrm{CHNN}^{10}{ }^{10}$ & 0.9656 & 31 & 4.05 & 311 & 234 & 77 & 0.329 \\
\hline \hline
\end{tabular}

where displacive phase transitions are sensitive to dopants and defects. It was considered that a small amount of defects can smear the first-order phase transition due to the reduction of the effects from order parameter fluctuations and a decrease in jumps of various thermodynamic quantities. The Curie constant was on the scale of $10^{5} \mathrm{~K}$, which further suggested that the first-order phase transition occurred at the transition temperature. BSNN materials followed the trend that was reported previously with $\mathrm{A}^{2+} \mathrm{B}^{4+} \mathrm{O}_{3}$ modified $\mathrm{NaNbO}_{3}$.

High field measurements were also carried out and plotted from BSNN-1, and the data were collected from the second cycle. Figure 4 shows the high field P-E loop and electronegativity difference vs. tolerance factor. Figure 4(a) shows the signature AFE double hysteresis loop of BSNN-1 and the current density $J$, which was calculated through
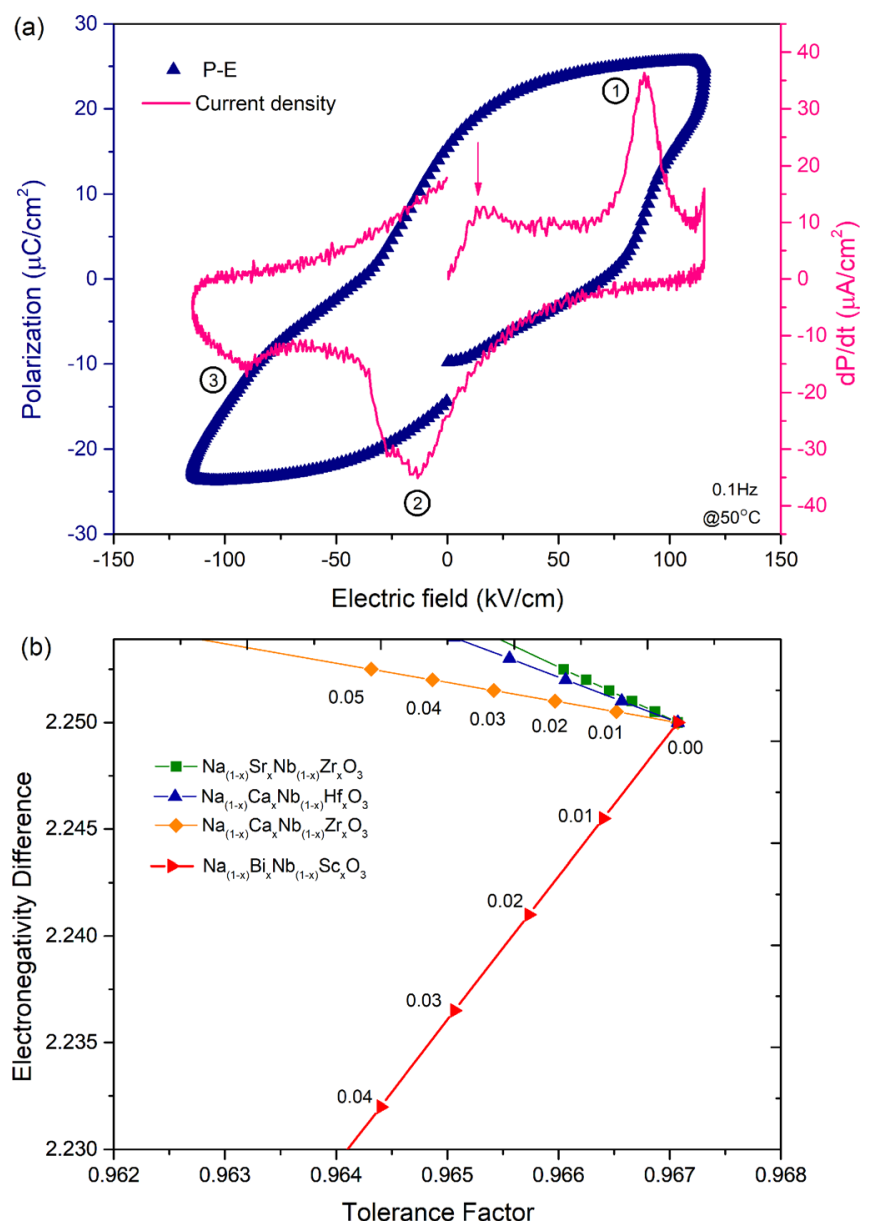

FIG. 4. (a) Electric field induced polarization double hysteresis loops and current density calculated by $\mathrm{dP} / \mathrm{dt}$. (b) X-t plot of $\mathrm{NaNbO}_{3}$ with $\mathrm{CaZrO}_{3}$, $\mathrm{SrZrO}_{3}, \mathrm{CaHfO}_{3}$, and $\mathrm{BiScO}_{3}$ dopants. $d P / d t$. Although the P-E loop was not perfectly shaped and saturated due to the conduction contributions caused by the loss of $\mathrm{Bi}$, it indicated that adding $\mathrm{BiScO}_{3}$ had the AFE phase stabilized in $\mathrm{NaNbO}_{3}$. Three clear peaks were seen in the current density curve and numbered sequentially. The sharp peak 1 in the first quadrant is due to the electric-fieldinduced AFE-FE switching, showing the critical field $E_{F}$ around $100 \mathrm{kV} / \mathrm{cm}$. Compared to the already reported CHNN AFE ceramics as listed in Table I, the $\mathrm{E}_{\mathrm{F}}$ of BSNN-1 is lower than those of reported CHNNs, which have lower tolerance factors than the BSNN-1. The trend agrees well with the results previously reported. ${ }^{10-12}$ Peaks 2 and 3 in the third quadrant indicate the AFE-to-FE back switching and switching with the applied opposite electric field, respectively. There should be a fourth peak representing the AFE-to-FE back switching in the fourth quadrant; but requiring the opposite field to induce the back switching, in this case, caused the absence in this quadrant. The arrow in Fig. 4(a) marks a hump in the first quadrant; previously, in those heavily modified materials, it was considered that the peak was associated with the phase transition to the incommensurate phase. However, due to an electric field being needed to induce the FE-to-AFE phase transition, it would be logical, in this scenario, that the peak was related to the FE-to-AFE phase transition due to potential overlapping of these two peaks. It was known that the relevant phases present similar energy in the vicinity of the phase boundary. Figure 4(b) shows the electronegativity difference $(\mathrm{X})$ vs. tolerance factor (t) of $\mathrm{NaNbO}_{3}$ with $\mathrm{CaZrO}_{3}, \mathrm{SrZrO}_{3}, \mathrm{CaHfO}_{3}$, and $\mathrm{BiScO}_{3}$. Compared to the already reported modification strategy by our group, ${ }^{10-12}$ adding $\mathrm{BiScO}_{3}$ lowered the tolerance factor faster than with the $\mathrm{A}^{2+} \mathrm{B}^{4+} \mathrm{O}_{3}$ end members. In addition, it showed not only the opposite trend but also a steeper slope of changing the $\mathrm{X}$. Instead of being more ionically bonded, adding $\mathrm{BiScO}_{3}$ increased the covalency of the bonds. It should be noticed that a more ionic character of the metal-oxygen bonds would lead to more thermally stable perovskite. ${ }^{40-42}$ Therefore, further increasing the amount of $\mathrm{BiScO}_{3}$ could eventually lead to destabilization of the perovskite structure.

In summary, an $\mathrm{AFE} \mathrm{xBiScO}_{3}-(1-\mathrm{x}) \mathrm{NaNbO}_{3}$ solid solution was fabricated and characterized. The stabilization of the AFE phase was proven both microstructurally and electrically. The P-E double hysteresis loop was induced and observed in BSNN-1. Additionally, the incommensurate phase was found in the AFE P phase region in BSNN-1, suggesting the existence of competition between AFE and FE phases in this composition. Furthermore, the results well 
agreed with the previously reported materials. ${ }^{10-12}$ It further broadened the lead-free AFE material family, and the universality of the tolerance factor rule is further verified.

The authors thank Amanda Baker exclusively for her help in managing all the work and apparatus in the lab and her advice for making this work possible. Moreover, the authors also thank Steve Perini and Jeff Long for their work and help in maintaining the dielectric and furnace lab and for providing technical support. This material is based upon work supported in part by the National Science Foundation, as part of the Center for Dielectrics and Piezoelectrics under Grant Nos. IIP-1361571 and 1361503.

${ }^{1}$ C. Kittel, Phys. Rev. 82, 729 (1951).

${ }^{2}$ E. Sawaguchi, H. Maniwa, and S. Hoshino, Phys. Rev. 83, 1078 (1951).

${ }^{3}$ X. Tan, C. Ma, J. Frederick, S. Beckman, and K. G. Webber, J. Am. Ceram. Soc. 94, 4091 (2011).

${ }^{4}$ L. E. Cross and B. J. Nicholson, London, Edinburgh, Dublin Philos. Mag. J. Sci. 46, 453 (1955).

${ }^{5}$ A. C. Sakowski-Cowley, K. Łukaszewicz, and H. D. Megaw, Acta Crystallogr. Sect. B Struct. Crystallogr. Cryst. Chem. 25, 851 (1969).

${ }^{6}$ E. A. Wood, R. C. Miller, and J. P. Remeika, Acta Crystallogr. 15, 1273 (1962).

${ }^{7}$ E. A. Wood, Acta Crystallogr. 4, 353 (1951).

${ }^{8}$ G. Shirane, R. Newnham, and R. Pepinsky, Phys. Rev. 96, 581 (1954).

${ }^{9}$ A. V. Ulinzheyev, O. E. Fesenko, and V. G. Smotrakov, Ferroelectr. Lett. Sect. 12, 17 (1990).

${ }^{10}$ L. Gao, H. Guo, S. Zhang, and C. A. Randall, J. Appl. Phys. 120, 204102 (2016).

${ }^{11}$ H. Guo, H. Shimizu, Y. Mizuno, and C. A. Randall, J. Appl. Phys. 117, 214103 (2015).

${ }^{12}$ H. Shimizu, H. Guo, S. E. Reyes-Lillo, Y. Mizuno, K. M. Rabe, and C. A. Randall, Dalton Trans. 44, 10763 (2015).

${ }^{13}$ H. Guo, H. Shimizu, Y. Mizuno, and C. A. Randall, J. Appl. Phys. 118, $54102(2015)$

${ }^{14}$ H. Guo, H. Shimizu, and C. A. Randall, J. Appl. Phys. 118, 174107 (2015).

${ }^{15}$ X. Tan, Z. Xu, X. Liu, and Z. Fan, Mater. Res. Lett. 6, 159 (2018).

${ }^{16}$ V. M. Goldschmidt, Naturwissenschaften 14, 477 (1926).
${ }^{17}$ I. M. Reaney and R. Ubic, Ferroelectrics 228, 23 (1999).

${ }^{18}$ P. L. Wise, I. M. Reaney, W. E. Lee, T. J. Price, D. M. Iddles, and D. S. Cannell, J. Eur. Ceram. Soc. 21, 1723 (2001).

${ }^{19}$ R. E. Eitel, C. A. Randall, T. R. Shrout, and S.-E. Park, Jpn. J. Appl. Phys., Part 1 41, 2099 (2002).

${ }^{20}$ D. I. Woodward, J. Knudsen, and I. M. Reaney, Phys. Rev. B 72, 104110 (2005).

${ }^{21}$ C. J. Stringer, T. R. Shrout, C. A. Randall, and I. M. Reaney, J. Appl. Phys. 99, 24106 (2006).

${ }^{22}$ R. D. Shannon, Acta Crystallogr. Sect. A 32, 751 (1976).

${ }^{23}$ S. Karimi, I. M. Reaney, Y. Han, J. Pokorny, and I. Sterianou, J. Mater. Sci. 44, 5102 (2009).

${ }^{24}$ S. Karimi, I. M. Reaney, I. Levin, and I. Sterianou, Appl. Phys. Lett. 94, 112903 (2009).

${ }^{25}$ D. Kan, L. Pálová, V. Anbusathaiah, C. J. Cheng, S. Fujino, V. Nagarajan, K. M. Rabe, and I. Takeuchi, Adv. Funct. Mater. 20, 1108 (2010).

${ }^{26}$ J. Chen and D. Feng, Phys. Status Solidi 109, 171 (1988).

${ }^{27}$ A. M. Glazer and H. D. Megaw, Acta Crystallogr. Sect. A 29, 489 (1973).

${ }^{28}$ I. P. Aleksandrova, O. V. Rosanov, A. A. Sukhovsky, and Y. N. Moskvich, Phys. Lett. A 95, 339 (1983).

${ }^{29}$ J. Chen and D. Feng, Phys. Status Solidi 109, 427 (1988).

${ }^{30}$ H. Guo, H. Shimizu, and C. A. Randall, Appl. Phys. Lett. 107, 112904 (2015).

${ }^{31}$ W. Brixel, M. L. Werk, P. Fischer, W. Bührer, J.-P. Rivera, P. Tissot, and H. Schmid, Jpn. J. Appl. Phys., Part 1 24, 242 (1985).

${ }^{32}$ C. A. Randall, S. A. Markgraf, A. S. Bhalla, and K. Baba-Kishi, Phys. Rev. B 40, 413 (1989).

${ }^{33}$ I. M. Reaney, D. I. Woodward, and C. A. Randall, J. Am. Ceram. Soc. 94, 2242 (2011).

${ }^{34}$ C.-J. Cheng, D. Kan, S.-H. Lim, W. R. McKenzie, P. R. Munroe, L. G. Salamanca-Riba, R. L. Withers, I. Takeuchi, and V. Nagarajan, Phys. Rev. B 80, 14109 (2009).

${ }^{35}$ D. Viehland, D. Forst, Z. Xu, and J.-F. Li, J. Am. Ceram. Soc. 78, 2101 (1995).

${ }^{36}$ S. K. Mishra, R. Mittal, V. Y. Pomjakushin, and S. L. Chaplot, Phys. Rev. B 83, 134105 (2011).

${ }^{37}$ H. D. Megaw, Ferroelectrics 7, 87 (1974).

${ }^{38}$ A. P. Levanyuk, S. A. Minyukov, and M. Vallade, J. Phys. Condens. Matter 9, 5313 (1997).

${ }^{39}$ A. P. Levanyuk and A. S. Sigov, Phase Transitions 11, 91 (1988).

${ }^{40}$ X. Wang, T. Wu, and M. R. Zachariah, J. Phys. Chem. C 121, 147 (2017).

${ }^{41}$ H. Thomann, Ferroelectrics 73, 183 (1987).

${ }^{42}$ C. A. Randall, A. S. Bhalla, T. R. Shrout, and L. E. Cross, J. Mater. Res. 5, 829 (1990). 